\title{
Prótesis DEL MIEMBRo INFERIOR DE LOS MOCHICAS
}

\author{
Prosthesis of the lower limb of the mochicas
}

\author{
Emiliano Paico Vílchez ${ }^{1}$ y Emiliano Paico Zumaeta ${ }^{2}$
}

\begin{abstract}
RESUMEN
El presente artículo permite evidenciar el ingenio y la sabiduría que tuvieron los cirujanos mochicas de crear una prótesis ortopédica de madera para menguar la discapacidad a quienes les habían amputado un pie. Así mismo, enfatiza la habilidad de los ceramistas mochicas para representar en sus obras, con una veracidad impresionante, a personas usando prótesis en reemplazo del pie que le fue amputado.
\end{abstract}

Palabras clave: Prótesis, amputación, pie, Mochica.

Abstract

This article shows the inventiveness and wisdom that the Mochica surgeons had in creating a wooden orthopedic prosthesis to diminish the disability of those who had had a foot amputated. It also emphasizes the ability of Mochicas ceramicists to represent in their works, with impressive veracity, people using prosthetics to replace the foot that was amputated.

Keywords: Prosthetics, amputation, foot, Mochica.

\section{INTRODUCCIÓN}

Es bien conocido por propios y extraños el éxito que tuvieron los cirujanos del Perú prehispánico, en los que ingenio y habilidad fueron dos factores primordiales para curar las enfermedades de los aborígenes. Los principios y los métodos utilizados son sorprendentes y fascinantes.

1 Profesor de la Facultad de Medicina de la Universidad Privada Antenor Orrego. Ex jefe del Servicio de Cirugía Pediátrica y del Servicio de Especialidades Quirúrgicas del Hospital Belén de Trujillo.

2 Estudiante de la Facultad de Ciencias de la Comunicación de la Universidad Privada Antenor Orrego. os cirujanos no solo se preocuparon por realizar oportuna y eficazmente la amputación de algún miembro inferior gravemente enfermo debido a traumatismo vascular irreparable, infección irreversible, tumor maligno, o por castigo por trasgredir una ley, sino que también se preocuparon por su rehabilitación, aplicando una prótesis de madera en reemplazo del pie amputado.

Lamentablemente, los cronistas de la conquista del Perú, quienes observaron de primera mano la cultura Inca y varias etnias costeñas como la Mochica y Chimú, no describen la práctica de amputaciones que nos hubiese permitido conocer cómo los aborígenes del antiguo Perú afrontaban la discapacidad motora que conlleva la mutilación de un pie.

Afortunadamente, existen fuentes arqueológicas comola cerámica que nos permite analizar con objetividad los maravillosos ceramios de la cultura Mochica que representan personas que usan una prótesis en reemplazo del pie que les fue amputado. Ceramios que están acorde con las evidencias osteológicas encontradas. Sin embargo, según la literatura consultada, existe poquísima bibliografía que se ocupe del tema. 
Este trabajo tiene el propósito de dar a conocer la inspiración que tuvieron los cirujanos del Perú prehispánico, específicamente los mochicas, para mejorar la calidad de vida de los amputados. Así mismo, dar a conocer la destreza que tuvieron los ceramistas de esa gran civilización para plasmar en sus obras, con una veracidad impresionante, a hombres con prótesis en reemplazo del pie que le fue amputado.

\section{Prótesis de madera en el PIE AMpUtado}

El uso de prótesis en los miembros inferiores data del antiguo imperio egipcio. Así mismo, las fuentes iconográficas testimonian el uso de prótesis en la época del imperio grecorromano. En el año 2013, en Hemmberg, en el sur de Austria, se encontró un esqueleto de un guerrero del siglo VI DC al que le faltaba el pie izquierdo, por encima del tobillo. En su lugar, un anillo de hierro y restos de madera fueron recuperados e interpretados por Binder como una prótesis que reemplaza el pie perdido. (1) En Europa representa uno de los ejemplos más antiguos de reemplazo protésico de extremidades asociado con el esqueleto de su usuario, nos dice el mismo Binder.

Las primeras evidencias de uso de prótesis en reemplazo de un pie amputado en los aborígenes peruanos se observan en ceramios de la civilización Mochica. Con el propósito de disminuir el grado de minusvalidez que presentaban los amputados, las hábiles manos de los cirujanos mochicas ingeniosamente confeccionaban y aplicaban prótesis de madera en reemplazo de un pie amputado. Esta prótesis permitía, con cierta comodidad, reintegrarse a sus actividades cotidianas o, por lo menos, integrarse a otras actividades en las que pudieran desempeñarse aceptablemente; es decir, mejoraba en ellos la calidad de vida.
La primera evidencia osteológica del uso de prótesis en los aborígenes del Perú, fue dada a conocer en 1913 por Lizardo Vélez López. (2) Este médico peruano describió un esqueleto moche sin pies, desenterrado en Mocollope en el valle de Chicama. El esqueleto fue encontrado con prótesis de madera, puestas sobre las extremidades distales de las tibias y peronés, Describió las prótesis como copas de madera revestidas en su interior con lana. Las superficies inferiores de las prótesis estaban desgastadas, lo que indicaba que habían sido usadas por un periodo de tiempo. Las tibias presentaban una morfología normal, sin evidencias de inflamación, infección u otra patología. El doctor Vélez afirmó que el esqueleto correspondía a una persona que sufrió la amputación de ambos pies, que estos fueron cercenados no como consecuencia de una enfermedad sino, probablemente, como una forma de castigo. Lamentablemente, Vélez no publicó fotos ni dibujos del esqueleto o de sus prótesis, ni se conoce la ubicación del material que fue estudiado.

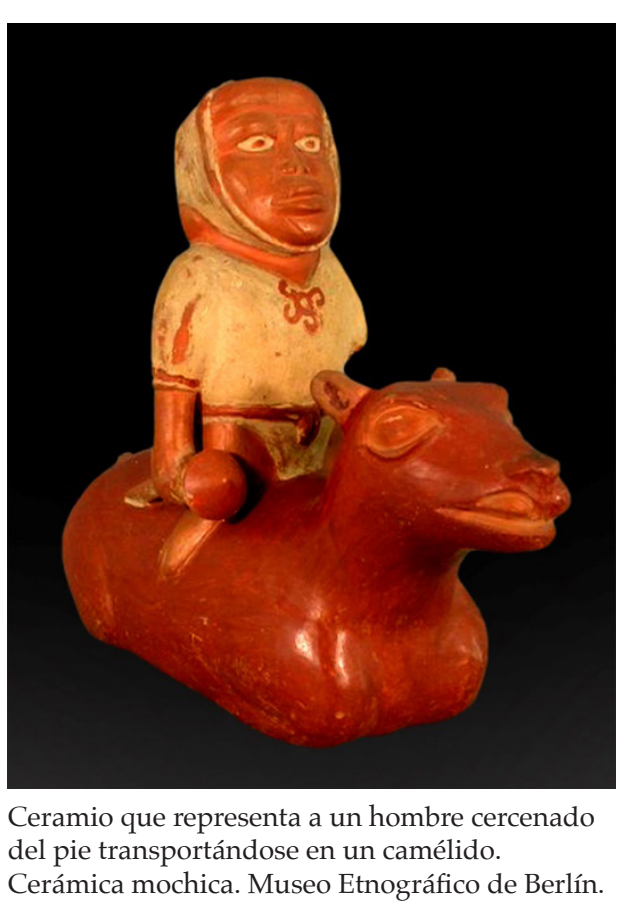




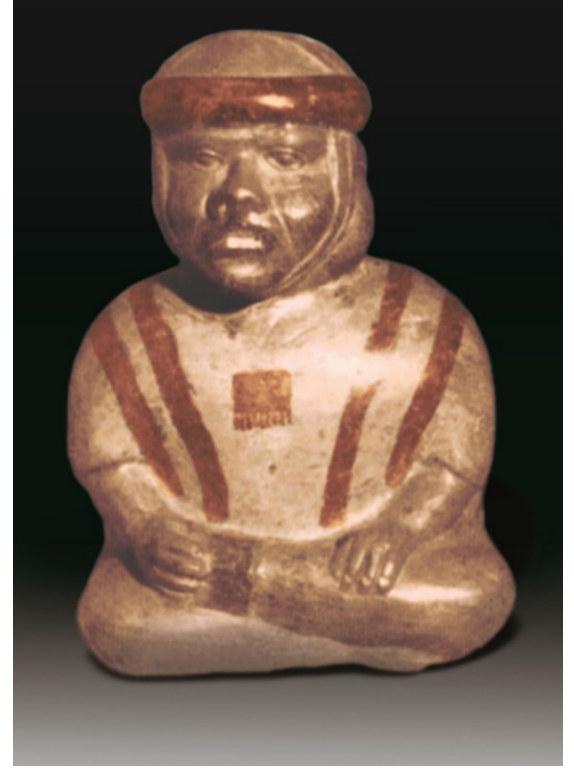

Representación de un varón colocándose una prótesis de madera en remplazo del pie izquierdo que le fue amputado. Cerámica mochica. Museo Nacional de Arqueología, Arqueología e Historia del Perú.
Desde 1913 hasta la actualidad no se han publicado similares evidencias osteológicas de prótesis en el aborigen peruano. Esto se debe, probablemente, a que las prótesis estaban hechas de madera y la materia orgánica se descompone con rapidez, salvo casos excepcionales.

En los años siguientes, se han dado a conocer ceramios que representan amputados de un pie que usan prótesis pero estas publicaciones son casos aislados, como los de los doctores Juan Lastres, Rafael Larco y Fernando Cabieses, entre otros. (3-5)

En 1999, Johnn Verano, en una revisión de colecciones publicadas encontró 99 ceramios que representan personas sin extremidades, identificando 24 de ellas con una prótesis en el que únicamente el pie fue amputado. (5)
El autor del presente estudio identificó en el Museo Arqueológico Cassinelli de Trujillo tres ceramios que representan a un individuo mochica con prótesis en lugar del pie amputado. Dos de ellos sólo presentan el pie amputado, no tienen otra amputación en el cuerpo, lo que indicaría que la amputación del pie fue por indicación médica. El otro, además del pie, también tenía amputado parte del labio superior, lo que indicaría que la amputación fue por motivos punitivos o religiosos.

En la actualidad, aún existe especulación en torno a la causa de la amputación en los aborígenes del Perú prehispánico. Numerosos investigadores sugieren que la amputación fue una forma de castigo, más que un procedimiento quirúrgico para tratar enfermedades. $(2,6-8)$ La evidencia que apoya esta interpretación proviene de la observación que muchas de las representaciones de

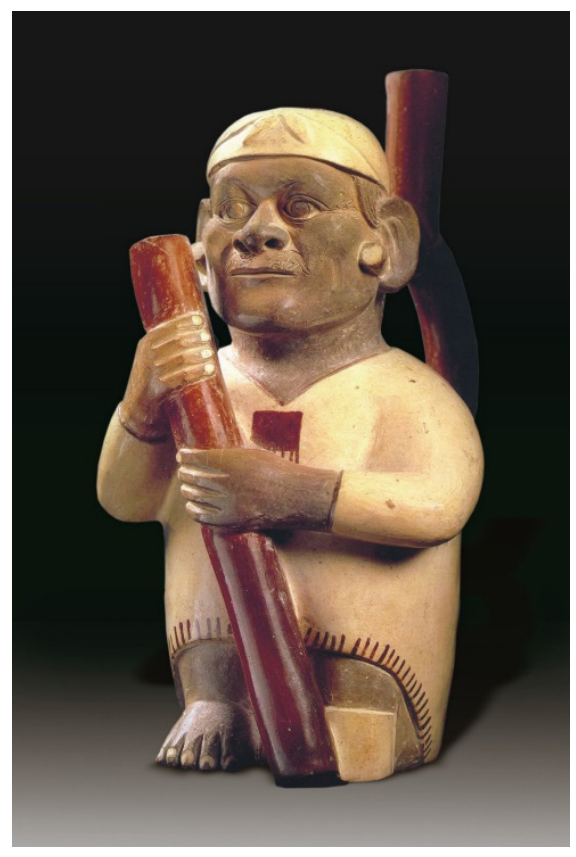

Representación de un hombre usando una prótesis de madera en remplazo del pie izquierdo amputado. Cerámica Mochica. Museo Arqueológico Rafael Larco Herrera. 


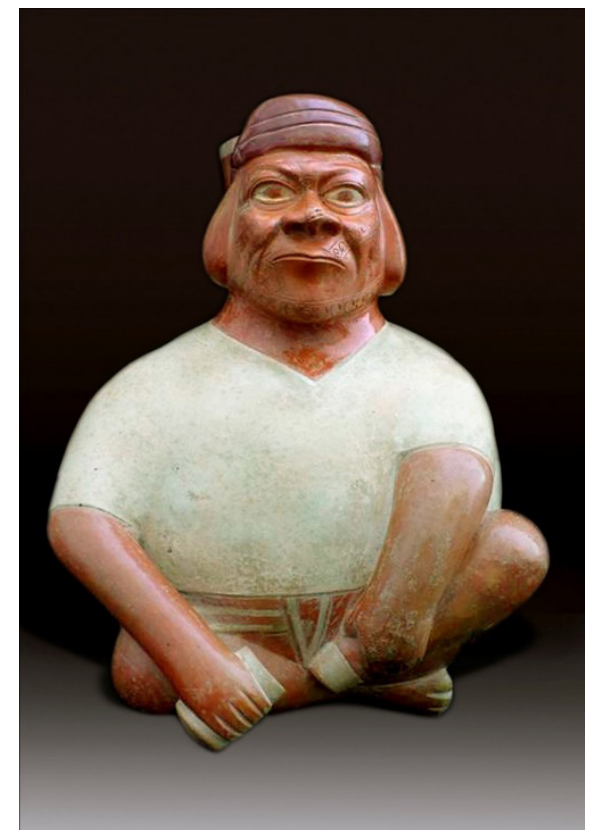

Personaje con escarificaciones decorativas en la cara colocándose una prótesis de madera en reemplazo del pie que le fue amputado. Cerámica mochica. Museo Arqueológico Cassinelli.

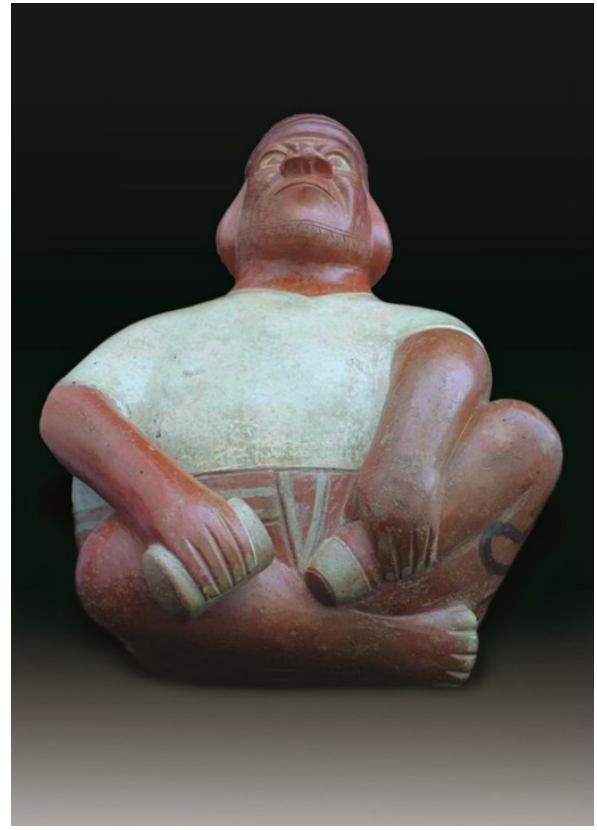

El mismo personaje de la figura precedente $\mathrm{Al}$ que se observa con mayor nitidez, colocándose la prótesis de madera. Cerámica mochica. Museo Arqueológico Cassinelli.

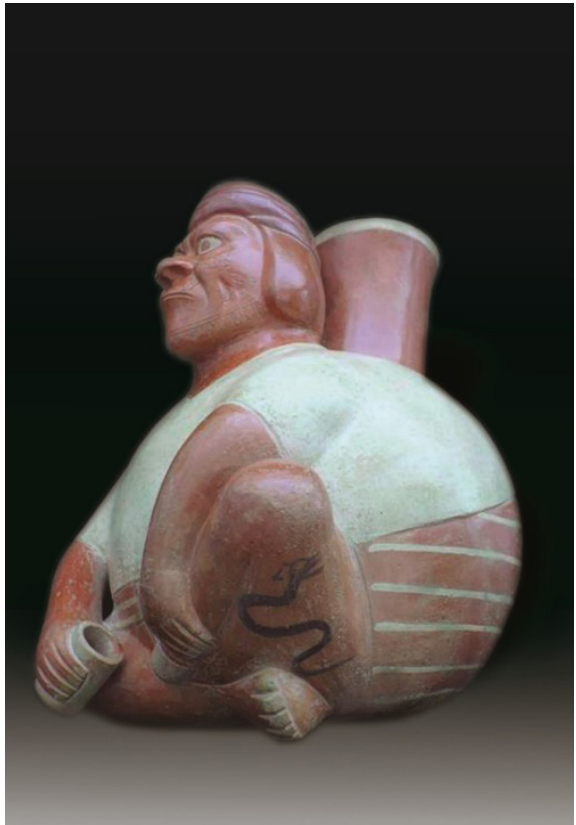

Personaje de la figura precedente a quien se observa, desde otro ángulo, colocándose la prótesis. En el muslo presenta un tatuaje en forma de serpiente. Cerámica mochica. Museo Arqueológico Cassinelli. personas moche sin extremidades también muestran labios y narices mutilados. Sin embargo, no se debe soslayar que la amputación del miembro pudo haber sido por alguna indicación médica debido a una enfermedad grave -infecciones irreversibles, traumatismos vasculares, tumores malignos- pues existen ceramios que representan individuos con sólo un pie amputado y en algunos de ellos con su respectiva prótesis.

Arsenault, en un estudio de ceramios mochica de individuos sin pies, presenta la hipótesis que la amputación puede haber sido una forma de mutilación social que marcaba a ciertos individuos como acompañantes especiales de la nobleza en la sociedad Mochica, así como en el mundo del más allá; $y$, consecuentemente, ellos estaban asociados con el poder. (9) Sea cual fuera la función o significado que tuvo la amputación en la civilización Mochica, se puede aseverar que los cirujanos mochicas realizaron amputaciones de miembros empleando una técnica quirúrgica fina y depurada dejando un muñón con los tejidos blandos para poder aplicar o no una prótesis, en reemplazo del pie amputado.

Las personas a quienes se les amputaba un pie tenían evidentemente dificultad para permanecer paradas por falta de estabilidad; de igual manera, tenían enorme dificultad para trasladarse de un lugar a otro, especialmente para las distancias largas. Seguramente, para menguar esta dificultad utilizaron un bastón. Pero, como la necesidad fue la mejor maestra del arte de la cirugía, fueron los cirujanos los que con admirable inspiración crearon un instrumento o aparato que sustituyera al pie cercenado, dando así solución, al menos en parte, a esta discapacidad o invalidez. (10) 


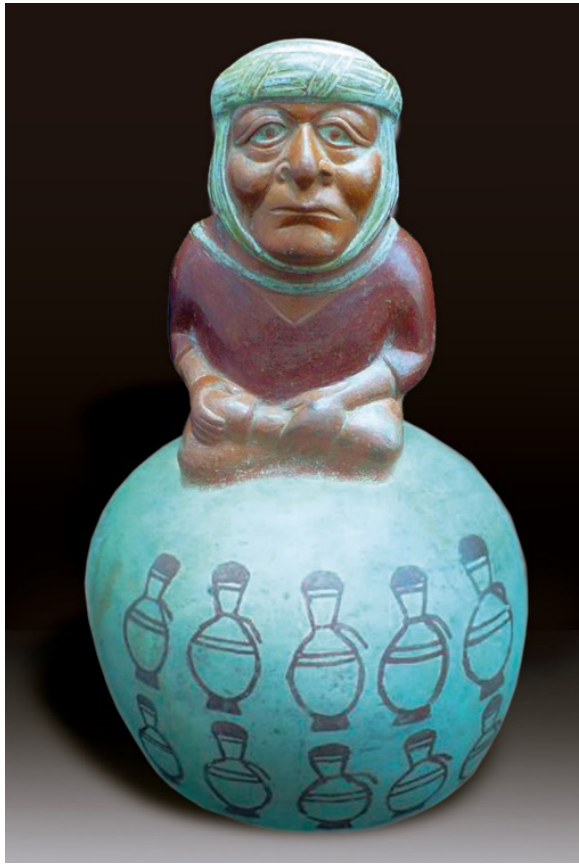

Representación de un hombre colocándose una prótesis de madera en remplazo del pie que le fue amputado. Cerámica mochica. Museo Arqueológico Cassinelli.

A juzgar por los hallazgos de Vélez López, la prótesis se confeccionaba de madera, obtenida de algún árbol que fuese resistente y fácil de tallar como el utilizado para confeccionar las porras o las mazas de los guerreros.(2) Las prótesis tenían la forma de copa o casco y en su interior le ponían lana para no lesionar el muñón de la pierna del amputado.

Según el estudio de los ceramios que representan personas a quienes les han amputado un pie y que en su reemplazo usaban prótesis, se puede expresar que el uso de la prótesis era para aquellas personas en las que les faltaba únicamente un pie, y que en el caso de faltarle los dos, no se utilizaba prótesis. Los personajes con prótesis en reemplazo del pie amputado que se observan en los ceramios están vestidos generalmente con una túnica y turbante. Unos pocos tienen tatuajes, pero ninguno lleva tocados elaborados $\mathrm{u}$ otras

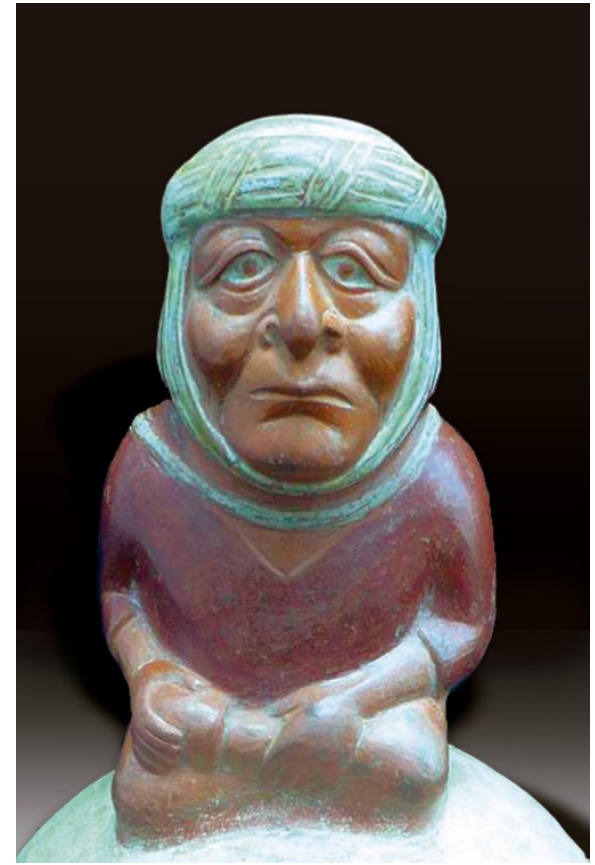

Personaje de la figura anterior al que se observa, con mayor nitidez, colocándose la prótesis de madera en remplazo del pie que le fue amputado. Cerámica mochica. Museo Arqueológico Cassinelli.

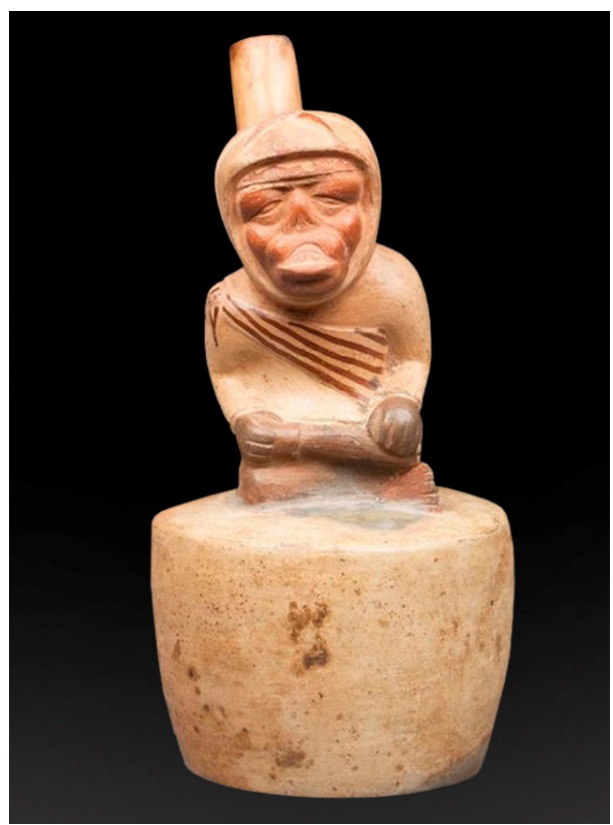

Hombre colocándose una prótesis de madera en remplazo del pie que le fue amputado. La amputación parcial de la nariz y del labio superior sugiere que fue víctima de castigo. Además tiene la cara edematosa. Cerámica mochica. Figura tomada de www.catawiki.com 


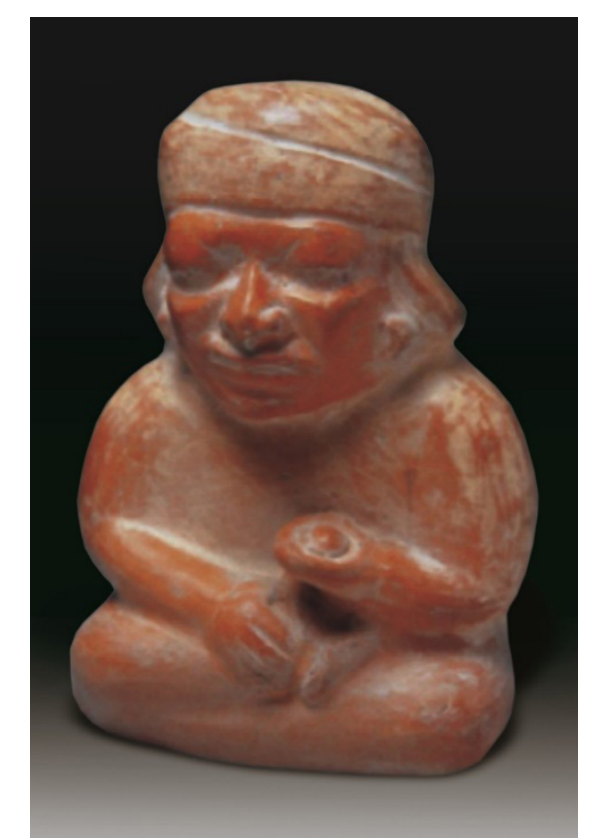

Ceramio que representa a un hombre colocándose una prótesis de madera en reemplazo del pie que le fue amputado. Cerámica mochica. Museo Arqueológico Rafael Larco Herrera.

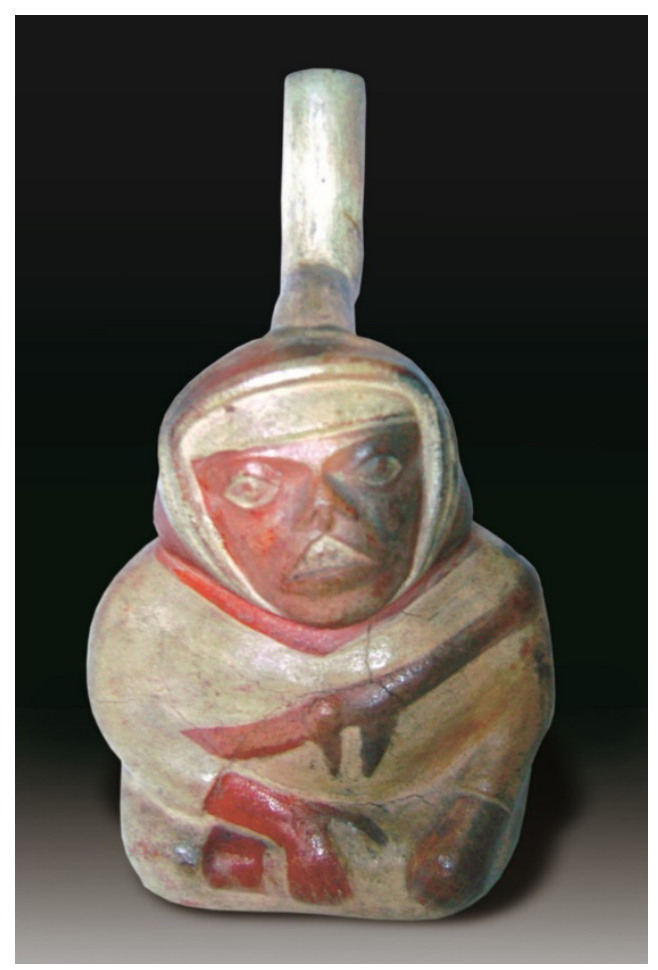

Hombre con prótesis de madera en remplazo del pie que le fue amputado. La amputación parcial del labio superior sugiere que fue víctima de castigo. Cerámica mochica. Museo Arqueológico Cassinelli.

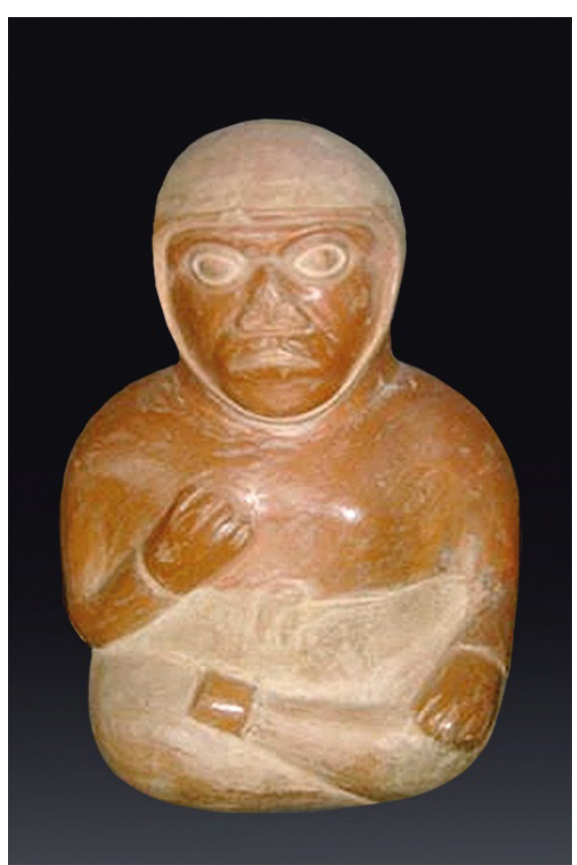

Hombre con prótesis de madera en remplazo del pie que le fue amputado. Cerámica mochica. Museo Nacional de Arqueología, Antropología e Historia del Perú.

indicaciones de alto rango social. La mayoría de ellos están sentados con las piernas cruzadas. Uno de los ceramios representa a un individuo con prótesis y con un bastón que seguramente le sirve para apoyarse y caminar mejor. También se ha observado representaciones en la misma persona que, además de la amputación del pie, tienen otras mutilaciones, especialmente de labio y nariz, que se confunden con las secuelas de la uta o leishmaniasis cutánea andina.

Algo que llama la atención en el estudio de estos ceramios es que las prótesis sólo se observan en varones y no mujeres, no obstante que la amputación de miembros también se realizaba en las mujeres, como Verano lo ha demostrado con evidencias osteológicas.(5) La explicación tal vez sería que en las sociedades precolombinas a los hombres les dieron una valoración diferente que a las mujeres. 


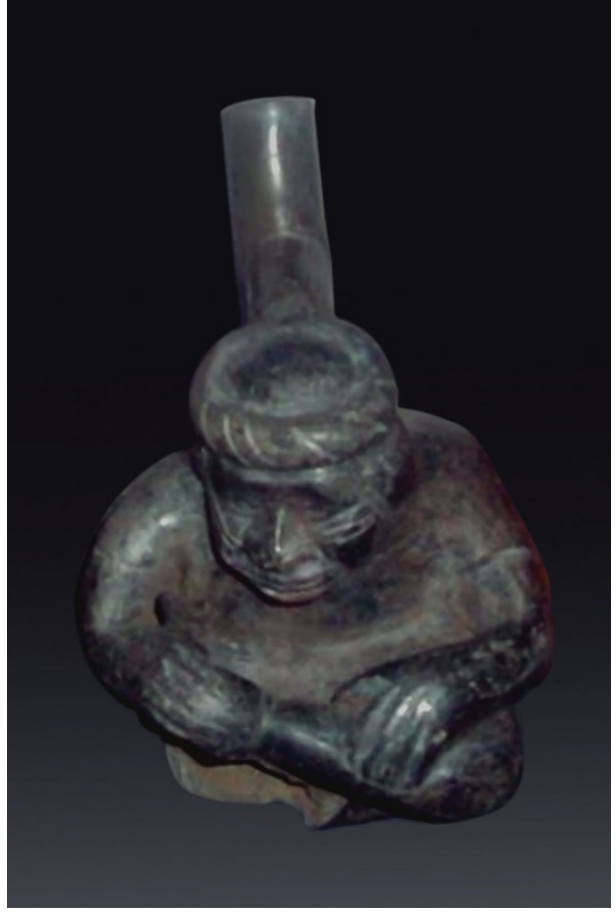

Anciano con prótesis de madera en remplazo del pie que le fue amputado. Cerámica mochica. Museo Nacional de Arqueología, Antropología e Historia del Perú.

A modo de conclusión, se puede decir que la inspiración del cirujano mochica para crear y aplicar una prótesis de madera en reemplazo del pie amputado permitió disminuir notablemente la discapacidad de los amputados. Así mismo, el arte de los ceramistas para plasmar en sus obras, con un realismo asombroso, a personas usando prótesis de madera en reemplazo del pie amputado, nos permite también conocer la habilidad de los cirujanos mochicas.

\section{RefERENCIAS Bibliográgicas}

1. Binder M, Eitler J, Deutscmann J, Ladstatter S, Glasser F and Fiedler D. Prosthetics in antiquity-An early medieval wearer of a foot prosthesis (6th century AD) from Hemmaberg/ Austria. International Journal of Paleopathology. 2016;12: 29- 60.

2. Vélez López, Lizardo. Las mutilaciones en los vasos antropomorfos del antiguo Perú. XVIII Session of the International Congress of Americanists. Londres; 1913: 267275.

3. Lastres, Juan B. La Historia de la Medicina: La Medicina Incaica. Tomo I. Universidad Nacional Mayor de San Marcos. Lima: Imprenta Santa María; 1951.

4. Larco Hoyle, Rafael. Los Mochicas. Tomos I - II. Museo Arqueológico Rafael Larco Herrera, Lima, 2001.

5. Cabieses Molina, Fernando. La salud y los dioses: La Medicina en el Antiguo Perú. Lima: Fondo Editorial de la Universidad Científica del Sur; 2007.

6. Verano, John W. Avances en la Bioantropología de los moches. En: Moche hacia el final del milenio. Actas del Segundo Coloquio sobre la Cultura Moche (Trujillo, 1 al 7 agosto de 1999). Lima: Santiago Uceda y Elías Mújica, editores, 2003: 1532 .

7. Tello. Julio C. Arte antiguo peruano. Álbum fotográfico de las principales especies arqueológica de la cerámica muchik existente en los museos de Lima. Inca. Revista trimestral de estudios antropológicos. Órgano del Museo de Arqueología de la Universidad Mayor de San Marcos de Lima. 11: VII-XXXVII 1924.

8. Urteaga Ballón, 0. Medical ceramic representation of nasal leishmaniasis and surgical amputation in ancient Peruvian civilization. En: Human Paleopathology, Current Syntheses and Future Options, D. J. Omer y A. C. Aufderheide, editores, Washington, D.C. y Londres, Smithsonian Institution Pnss. 1991.

9. Arsenault, Daniel: El Personaje del pie amputado en la cultura mochica del Perú: Un ensayo sobre la arqueología del poder. Latin American Antiquity. Vol. 4, No. 3, 1993.

10. Diepgen, P: Historia de la Medicina. Berlín, 1914.

\section{CORRESPONDENCIA: epaicov@gmail.com}

Fecha de recepción: 12-01-2020.

Fecha de aceptación: 20-02-2020. 